Int. J. Electrochem. Sci., 14 (2019) 5200 - 5210

\title{
Fabrication and Characterization of Polypyrrole/Reduced Graphene-Oxide Films for Electrochemical Capacitors
}

\author{
O. J. Márquez-Calles ${ }^{l}$, R. D. Martínez-Orozco ${ }^{l}$, N. V. Gallardo-Rivas ${ }^{1}$, A. M. Mendoza-Martínez ${ }^{l}$, \\ R. Mayén-Mondragón ${ }^{2}$ and U. Páramo-García ${ }^{*}$ \\ ${ }^{1}$ Tecnológico Nacional de México/Instituto Tecnológico de Cd. Madero, Centro de Investigación en \\ Petroquímica, Prol. Bahía de Aldhair y Av. de las Bahías, Parque de la Pequeña y Mediana Industria, \\ 89600, Altamira, Tamaulipas, México. \\ ${ }^{2}$ Polo Universitario de Tecnología Avanzada, Facultad de Química, Universidad Nacional Autónoma \\ de México, 66629, Apodaca, Nuevo León, México \\ *E-mail: uparamo@itcm.edu.mx
}

doi: $10.20964 / 2019.06 .05$

Received: 13 November 2018 / Accepted: 23 March 2019 / Published: 10 May 2019

The co-electrodeposition and characterization of Polypyrrole (PPy)/Reduced Graphene Oxide (RGO) films $(1: 5,1: 10$ and 1:15 mass ratio) for electrochemical capacitors are presented in this work. Polypyrrole polymerization and incorporation of RGO were conducted simultaneously in order to attain the best possible dispersion of the latter within the polypyrrole matrix. The materials were characterized by scanning electron microscopy, Fourier-transform infrared spectroscopy, X-ray diffraction and electrochemical impedance spectroscopy (EIS). The effect of the RGO:PPy mass ratio on the film electrochemical and morphological properties was evaluated. The results show a good dispersion of RGO was attained, along with a good cycling stability of the composite materials. Agglomeration of the PPy was however observed. EIS analysis showed the composite capacitance increases as the RGO content is increased. The polarization resistance, on the other side, increased unexpectedly for larger PPy contents due mainly to agglomeration effects and over-oxidation of the conductive polymer. A finer dispersion of the PPy phase is imperative to improve the electrochemical properties of the composite.

Keywords: RGO:PPy, composite materials, capacitors, thin films, electrodeposition.

\section{$\underline{\text { FULL TEXT }}$}

(C) 2019 The Authors. Published by ESG (www.electrochemsci.org). This article is an open access article distributed under the terms and conditions of the Creative Commons Attribution license (http://creativecommons.org/licenses/by/4.0/). 